\title{
Global transcriptome changes of elongating internode of sugarcane in response to mepiquat chloride
}

Rongfa Chen, Yegeng Fan, Huiwen Zhou, Shanping Mo, Zhongfeng Zhou, Haifeng Yan, Ting Luo, Xing Huang, Mengling Weng, Prakash Lakshmanan, Yangrui Li, Lihang Qiu* (i) and Jianming Wu*

\begin{abstract}
Background: Mepiquat chloride (DPC) is a chemical that is extensively used to control internode growth and create compact canopies in cultured plants. Previous studies have suggested that DPC could also inhibit gibberellin biosynthesis in sugarcane. Unfortunately, the molecular mechanism underlying the suppressive effects of DPC on plant growth is still largely unknown.

Results: In the present study, we first obtained high-quality long transcripts from the internodes of sugarcane using the PacBio Sequel System. A total of 72,671 isoforms, with N50 at 3073, were generated. These long isoforms were used as a reference for the subsequent RNA-seq. Afterwards, short reads generated from the Illumina HiSeq 4000 platform were used to compare the differentially expressed genes in both the DPC and the control groups. Transcriptome profiling showed that most significant gene changes occurred after six days post DPC treatment. These genes were related to plant hormone signal transduction and biosynthesis of several metabolites, indicating that DPC affected multiple pathways, in addition to suppressing gibberellin biosynthesis. The network of DPC on the key stage was illustrated by weighted gene co-expression network analysis (WGCNA). Among the 36 constructed modules, the top positive correlated module, at the stage of six days post spraying DPC, was sienna3. Notably, Stfo sulfotransferase, cyclin-like F-box, and HOX12 were the hub genes in sienna3 that had high correlation with other genes in this module. Furthermore, the qPCR validated the high accuracy of the RNA-seq results.
\end{abstract}

Conclusion: Taken together, we have demonstrated the key role of these genes in DPC-induced growth inhibition in sugarcane.

Keywords: Mepiquat chloride, Sugarcane, Full-length transcriptome, RNA-seq, Growth, Internode

\section{Background}

Hormone regulation in plant culturing has been widely used to control the quality of agricultural and horticultural products [1]. Several hormones are known to affect the regulation and co-ordination of plant growth [2]. To date, auxins [3], gibberellins (GA) [4], cytokinins (CTK)

\footnotetext{
*Correspondence: qiulihang2017@126.com; wujianming2004@126.com Sugarcane Research Institute, Guangxi Academy of Agricultural Sciences/ Sugarcane Research Center, Chinese Academy of Agricultural Sciences, No. 172, East Daxue Road, Nanning 530007, Guangxi, China
}

[5], abscisic acid (ABA) [6], ethyne (ETH) [7], and brassinosteroids (BR) [8] have been the most popular hormones for stimulating growth in crops. However, growth performance is not the only parameter that is sought after in the increasing demands made by farmers. For example, with excessive vegetative growth, crops such as cotton and sugarcane can hardly be controlled leading to height irregularities in farmland, which results in low productivity $[9,10]$. Thus, other regulated chemicals

C C The Author(s). 2021 Open Access This article is licensed under a Creative Commons Attribution 4.0 International License, which permits use, sharing, adaptation, distribution and reproduction in any medium or format, as long as you give appropriate credit to the original author(s) and the source, provide a link to the Creative Commons licence, and indicate if changes were made. The images or other third party material in this article are included in the article's Creative Commons licence, unless indicated otherwise in a credit line to the material. If material is not included in the article's Creative Commons licence and your intended use is not permitted by statutory regulation or exceeds the permitted use, you will need to obtain permission directly from the copyright holder. To view a copy of this licence, visit http://creativecommons.org/licenses/by/4.0/. The Creative Commons Public Domain Dedication waiver (http://creativecommons.org/publicdomain/zero/1.0/) applies to the data made available in this article, unless otherwise stated in a credit line to the data. 
have been introduced as alternatives to inhibit the relevant hormonal pathways.

Mepiquat chloride (DPC) is a well-known chemical that controls organism growth by suppressing the GA pathways $[11,12]$. As an exogenous plant growth regulator, DPC is a water-soluble substance that can be applied via spraying in farmlands [13]. With low-dose DPC treatment, studies have seen reduced internode elongation and plant height [13, 14]. Additionally, recent studies have revealed that DPC could also regulate the synthesis of endogenous hormones, carbohydrates, enzymes, and other organic molecules $[15,16]$. DPC treatment increased concentrations of chlorophyll, free proline, and soluble proteins, but depressed malondialdehyde levels, contributing to improved resistance to stress [17-19]. In addition, DPC promoted the increase of calcium and phosphorus levels in leaves to strengthen their ability to resist disease $[20,21]$. Theoretically, it does this by regulating CTKs and the synthesis of GAs, as well as controlling the ratios of CTKs:GAs- and DPCmediated rhizogenesis [22]. However, the function and regulatory role of DPC is far from being systematically understood.

Sugarcane is a major agricultural crop for sugar production worldwide [23-25]. About $80 \%$ of the world's sugar is isolated from sugarcane, making it a critical bioenergy crop [26]. Sucrose is primarily generated in the crop's stem and higher shoot $[27,28]$, and the internode elongation of stems is associated with the deposition of sucrose [29]. In this situation, GA is employed to stimulate internode elongation [30]. However, rapid stem growth may lead to lower sucrose accumulation $[31,32]$. Therefore, how to achieve an ideal balance for the most productive rate of stem growth is the key question in sugar production. In an attempt at solving this problem, DPC was introduced to control the negative effects of GA treatment [33]. Although DPC is widely recognized as a regulator of GA and promotes resistance to stress [34, 35], its underlying molecular mechanism is still unknown. Moreover, to venture into this knowledge would require thorough scanning of the systematic regulation of DPC in plants.

A previous study showed that during internode elongation, regulation by the microRNA-mRNA network in zeatin biosynthesis, nitrogen metabolism, and plant hormone signal transduction pathways played a part in stem growth in sugarcane [36, 37]. These effects may be mediated by GA20-oxidase (GA20-OX1) and a gibberellin receptor (GID1). DPC has shown inhibitory effects on GA generation by suppressing the activities of copalyl diphosphate synthase and ent-kaurene synthase [13]. These results revealed the molecular mechanism in controlling growth performance by DPC. However, a vast amount of information about the roles of DPC in growth and resistance to stress remains unknown. Herein, we used the mathematical method, weighted gene coexpression network analysis (WGCNA), to identify key gene networks and hub genes [38-40]. The present study focused on the transcriptome changes induced by DPC treatment using the Illumina HiSeq 4000 platform. The evidence presented here provides new insights on DPC function in controlling stem growth as well as regulating resistance to stress, which are the two most economically important traits in sugarcane.

\section{Results}

\section{Growth performance}

The growth performance of each group at different days were shown in Fig. 1a. At the beginning of the experiment (0 days), no significant difference was found between the control and DPC groups $(P>0.05)$. However, the sugarcane heights on days 3,6 , and 12 as well as that of mature sugarcane, were significantly higher in the control than in the DPC groups $(P<0.05)$ (Fig. 1b). Contrary to the sugarcane height, the growth rates of DPC groups were significantly lower on days 3,6 , and 12 when compared to the control $(P<0.05)$ (Fig. 1c). Moreover, all the internodes were significantly longer in the control group (Fig. 1d).

\section{Full-length transcriptome of sugarcane}

To generate a high-accuracy reference for read mapping data, full-length mRNA sequencing was performed using the PacBio Sequel platform on internodes from mature sugarcane. A total of 17 billion raw reads were obtained. The average length was $2718 \mathrm{bp}$ and N50 was $3011 \mathrm{bp}$. After circular-consensus sequence (CCS) extraction, 428, 444 reads were identified. Among these reads, 348,840 $(81.42 \%)$ were full-length reads containing $5^{\prime}$ adaptors, poly(A) tail signals, and 3' adaptors. Meanwhile, 999 million full-length non-chimeric (FLNC) reads with an average length of $2906 \mathrm{bp}$ were identified. These FLNC reads from the cDNA library contain repetitive isoforms that provide data for analysis of isoforms by alignment and assignment to different clusters. The present fulllength transcriptome generated 72,671 isoforms. Of these, the average length was $2888.94 \mathrm{bp}$ and the N50 was 3073 (Additional file 2).

The isoforms were annotated by aligning the protein and nucleotide databases. In total 69,803, 56,843, 47,438, and 30,240 isoforms were annotated from $\mathrm{nr}$, Swissport, KOG, and KEGG, respectively. Combining these results, a total of 69,867 isoforms were annotated (Additional file 3). The isoforms were also aligned to different species. The five species with the most hit sequences were Saccharum spontaneum, Setaria italica, the Oryza sativa Japonica group, Dichanthelium oligosanthes, and Sorghum bicolor. In addition to this, these isoforms were 
annotated by GO terms assigned to three categories: biological process (50,805 isoforms), cellular component $(32,922$ isoforms), and molecular function (26,696 isoforms). In the biological process category, metabolic process (13,462 isoforms) and cellular process $(12,836$ isoforms) were the two most functional terms. Cell (7598 isoforms) and cell parts (7597 isoforms) were the two most functional terms in the cellular component category, while in the molecular function category, catalytic activity (13,086 isoforms) and binding (11,642 isoforms) were the two most functional terms (Fig. 2c).

\section{DEGs by DPC treatment}

The 150 pair-end reads were obtained for DEG analysis. In total, 1,404,530,300 raw reads were generated from 18 cDNA libraries using the Illumina HiSeq 4000 platform. After trimming the adaptor and removing the lowquality reads, 1,380,323,402 (98.28\%) reads were retained as high-quality clean reads. These clean reads were mapped to the reference as the full-length transcriptome. The mapping ratios for the $18 \mathrm{cDNA}$ libraries ranged from 73.97 to $83.78 \%$. Using these data, the normalized expression data were calculated and normalized gene expression was analyzed by PCA (Fig. 3a). Two clusters were clearly defined by PCA, which contained the DPC group and control for each cluster. The first principal component, PC1, summarized $30.7 \%$ of the whole variability and discriminated samples according to the treatment. The second principal component, PC2, and the third principal component, $\mathrm{PC} 3$, summarized 25.1 and $17.4 \%$ of the whole variability and discriminated samples, respectively. The DEG analysis showed that the comparison between $\mathrm{C} 2$ and D2 groups had the most DEGs (a total of 6012 genes, which contained 3227 upregulated genes and 2785 downregulated genes). D1 showed more upregulated genes compared to D2 and D3 groups, while less downregulated genes were found in D1 than in D2 and D3 groups. In addition, most DEGs in C2-vs-D2, C1-vs-C2 (2895 DEGs), and D1-vsD2 (3157 DEGs) also showed a large number of differentially expressed genes (Fig. 3b).

\section{Functional analyses of DEGs between C2 and D2 groups}

To illustrate the functions of the DEGs after DPC treatment, GO enrichment and KEGG enrichment analyses of the comparison of $\mathrm{C} 2$ and D2 with the most DEGs were performed. The upregulated and downregulated genes were annotated in 29 and 37 GO terms, respectively (Fig. 4a, b). The GO enriched terms with the four most upregulated genes were DNA metabolic process, negative regulation of biological process, regulation of translation, and regulation of cellular amide metabolic process. Meanwhile, the GO enriched terms with the two most downregulated genes were single-organism transport and single-organism localization (Additional file 4). KEGG enrichment analysis showed that 17 and 30 pathways were enriched in the upregulated and downregulated genes, respectively (Fig. 5a, b). Either for the upregulated genes or downregulated genes, metabolic pathways and biosynthesis of secondary metabolites were the top two enrichment KEGG pathways with the most genes. Among the upregulated genes, 55 were found to increase in the plant hormone signal transduction pathway. Meanwhile, phenylpropanoid biosynthesis, flavonoid biosynthesis, favone and flavonol biosynthesis, and glucosinolate biosynthesis were enriched in the downregulated genes (Additional file 5). These KEGG pathways were associated with the growth and development of internodes.

\section{WGCNA and hub genes}

The WGCNA divided the genes into 36 modules (Fig. 6). Based on the identification of DEGs, we focused on the D2 group. This group contained significant gene expression changes, which is the crucial stage for internode elongation. We found that sienna3 was the module that most significantly correlated with the D2 stage $(p=1 \mathrm{e}-4)$ (Additional file 6) (Fig. 7). The sienna3 module contained 33 genes and the top three hub genes, namely Stf0 sulfotransferase, cyclin-like F-box, and HOX12, were identified in this module. These three hub genes correlated with 30 genes (Additional file 7) (Fig. 8).

\section{Validation of RNA-seq result}

qPCR was used to validate the RNA-seq results. Randomly, nine genes were selected for the analysis. Except for GID2 and PBS1, the other six tested genes, GA2OX1, GID1, MPK4, CML49, PRPF8, and ACO2, showed similar qPCR results to those of the RNA-seq. Moreover, the expression trend of six out of eight genes from $\mathrm{qPCR}$ and RNA-seq was highly consistent, indicating that the majority of genes had the same tendency (Fig. 9). The three hub genes, Stfo sulfotransferase, cyclin-like F-box, and HOX12, were also analyzed by qPCR, and the results were similar between both qPCR and RNA-seq (Fig. 10). These results showed the high reliability of the RNA-Seq data.

\section{Discussion}

Sugarcane is the main source of sugar in the industry, accounting for $79 \%$ of the sugar production worldwide. Attempts at developing techniques for controlling the growth of sugarcane, accelerating the yields, and culturing biotechnology for sugarcane resulted in varied uses of GA and DPC. These are two chemicals that regulate plant growth in sugar farming with different effects. GA stimulates sugarcane internode elongation by regulating the genes associated with zeatin biosynthesis, nitrogen 
metabolism, and plant hormone signal transduction pathway [41], while DPC suppresses sugarcane growth. However, compared to the clear mechanism of GAstimulated growth, the molecular mechanisms of DPC are unclear. Thus, in the present study, we focused on the transcriptomic regulation by DPC on sugarcane and discussed the key genes that mediate its growthsuppressive effect.

First, to obtain a high-quality reference for gene annotation, we generated a full-length transcriptome from sugarcane, which was sequenced using the PacBio Sequel platform, thereby generating 72,671 isoforms. Compared to Illumina platforms, the PacBio Sequel platform could gain longer transcripts, which is an advantage in the construction of high-quality references for short sequence analysis. The present study generated reads with N50 at 3011 bp. These long reads guarantee longer contigs and isoforms for subsequent transcriptome analysis [42]. Notably, it turns out that the N50 was 3073 for the isoforms in the present study. Sugarcane is a widely cropped plant and to date, a large number of different varieties have been developed. Of these are the Guitang varieties developed from Guangxi, which have become a series of varieties planted in southern China [43]. GT42, belonging to the Guitang varieties, is a new breeding line with higher sugar productivity [43]. Although the genome of sugarcane was reported on until 2018, the genome data may differ among varieties [44]. Our study is the first to report the full-length transcriptome of GT42. It is our belief that these data would accelerate the studies on new high-yielding crops and provide a highquality reference when analyzing the Illumina short reads. They also provided a chance to illustrate the function of internodes in GT42. Notably, the most abundant GO term regarding the biological process of GT42 isoforms, included metabolic process and cellular process. Thus, this functional isoform showed similar assignment of function to previous results from sugarcane [44-46]. Based on these data, GT42 had a functional constitution similar to that of other sugarcane varieties. The present full-length transcriptome was the first to generate general information on GT42 and provided a high-quality reference transcriptome for further investigation of this variety.

DPC is one of the most successful and widely used chemicals for regulating plant growth. Its application has been shown to reduce internode length and leaf size in cotton and sugarcane [12]. The present study also suggested that DPC inhibited internode length in GT42, which was similar to previous results. After understanding the effects of DPC on internode growth, the next question is to determine the molecular mechanism of the function of DPC in sugarcane. In doing so, we used RNA-seq to show the whole profile of gene expression regulation. Using the HiSeq technique, we obtained millions of short reads to reveal the expression in different stages induced by DPC treatment. Thanks to the highquality full-length transcriptome data, the mapping ratios for these libraries covered 73.97 to $83.78 \%$. The comparison between C2 and D2 had the most DEGs, which was 6012 genes. This number of DEGs was much higher than that in C1-vs-D1 and C3-vs-D3, suggesting that the gene expression changes between the control and DPC treatment were mainly in the second stages; namely, after six days post application via spraying. In a study on cotton spraying with DPC, the $96 \mathrm{~h}$ post spraying significantly had the most DEGs compared to the 48 $\mathrm{h}$ and $72 \mathrm{~h}$ stages. From this, it seems that DPC resulted in changes in gene expression over the long-term course of four to six days. Gene expression regulation by DPC is not an acute effect. After 10 days, the effects of DPC on gene expression were diminished. We supposed that the most effective period of DPC-regulated gene expression was six days.

The KEGG enrichment analysis showed that the expression levels of 55 genes in the plant hormone signal transduction pathway had increased from DPC treatment. Internode growth is controlled by several hormonal genes, such as $\mathrm{G}$ biosynthesis genes, auxin-related genes, and ethylene genes. It has been reported that GA treatment can significantly upregulate these genes, while DPC may suppress hormone expression. Specifically, in Agapanthus praecox, auxin-related genes were shown to be inhibited by DPC treatment [47]. Surprisingly, the present study also indicated that DPC increased the expression levels of several hormonal genes. This difference may be due to the different species examined. Therefore, sugarcane may have a different response to DPC at the molecular level. We also found that several key pathways could be downregulated by DPC, such as phenylpropanoid biosynthesis, flavonoid biosynthesis, favone and flavonol biosynthesis, and glucosinolate biosynthesis, which were enriched. The phenylpropanoid pathway provides metabolites for plant growth, which contributes to the requirement of lignin biosynthesis [48]. Moreover, favone, flavonol, and glucosinolate are key metabolites for internode growth $[49,50]$. Flavonol biosynthesis could be affected by light intensity and, in previous studies, led to different growth appearances in Ginkgo (Ginkgo biloba) [51]. Meanwhile, the glucosinolate concentration, influenced by sulfur and nitrogen supplementation, was associated with the growth of broccoli [52]. The downregulation of genes in these pathways may lead to the shortening effects of sugarcane internodes.

To determine the key gene modules and hub genes from the effects of DPC treatment, WGCNA was performed. In this sienna3, 33 genes were found highly 

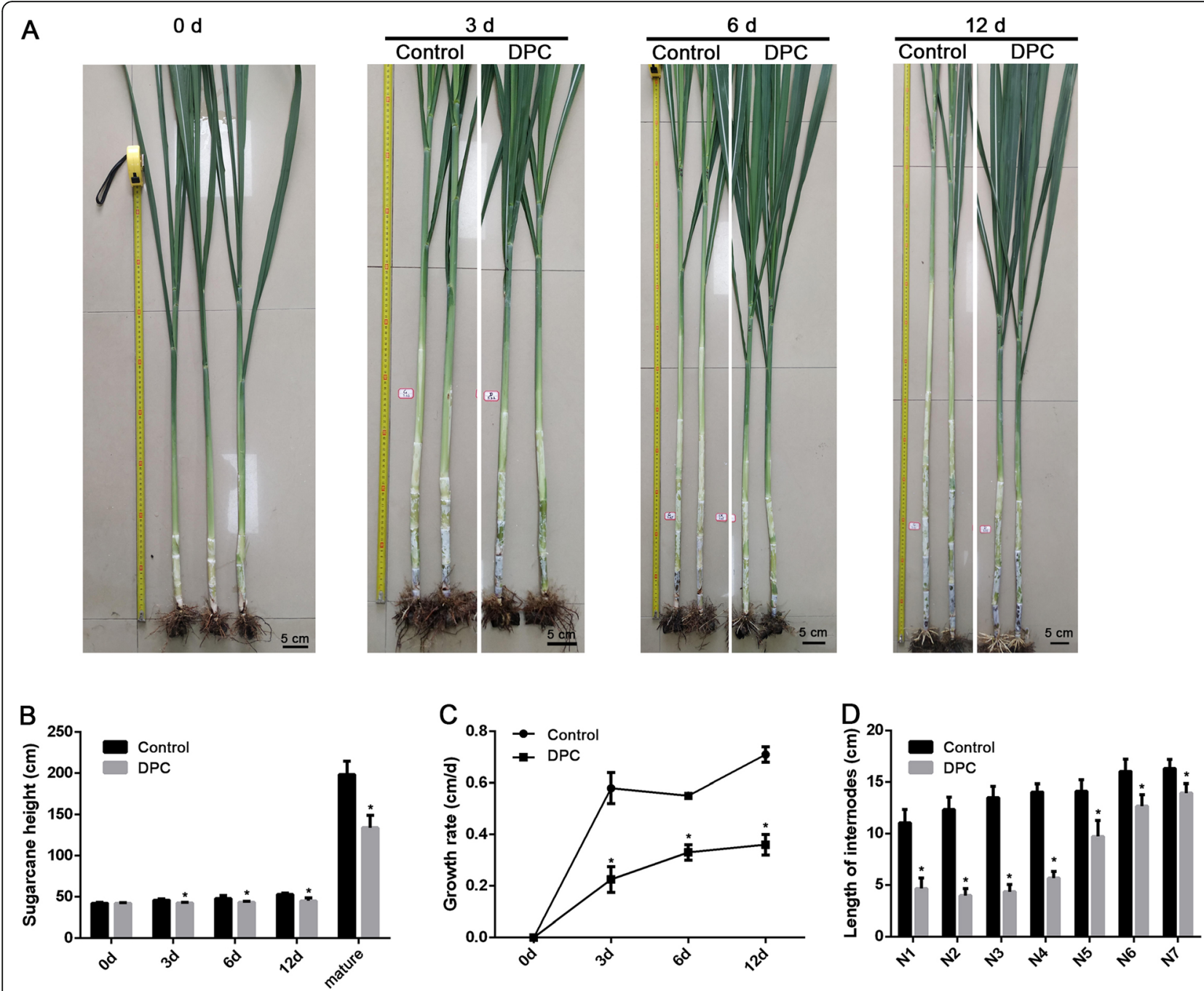

Fig. 1 Effects of DPC on sugarcane growth performance on different days after treatment. a The growth performance of sugarcane in 0, 3, 6, and 12 days from control and DPC groups. b The height of sugarcane on different days after DPC treatment $(n=4)$. $\mathbf{c}$ The growth rate of sugarcane on different days after DPC treatment $(n=4$; mature period, $n=10)$. $\mathbf{d}$ The internode length of sugarcane in mature sugarcane after DPC treatment. * indicates $P<0.05$

correlated with the three hub genes. Therefore, the most critical genes play a key role in the module. Hub genes are the genes that correlate with other genes in expression levels, which could be identified by mathematical methods. The top three identified in this study were Stf0 sulfotransferase, cyclin-like F-box, and HOX12. Stfo belongs to the sulfotransferase family, which affects root development processes, elongation growth, and gravitropism [53]. In several plants, including Medicago truncatula, Lotus japonicus, and Arabidopsis thaliana, cyclin-like F-box genes were expressed in all the tissues containing highly active dividing cells. Knockdown of this gene resulted in the accumulation of CYCB1:1, suggesting that the cyclin-like F-box gene could regulate the cell cycle in dividing cells [54]. Furthermore, it has been reported that HOX12 regulates panicle exsertion via modulating EUI1 gene expression [55]. These three hub genes were correlated with the other genes in the sienna3 modules. Based on this information, it could be concluded that Stf0 sulfotransferase, cyclin-like F-box, and HOX12 mediated a gene group and constituted a gene network that contributed to the DPC-induced effects on sugarcane growth.

\section{Conclusion}

In summary, the full-length GT42 transcriptome was first reported in this study, thereby providing an informative resource for sugarcane breeding and transcriptome analysis. RNA-seq suggested that the main effects of DPC on sugarcane gene expression occurred six days post spraying. Furthermore, the significantly 


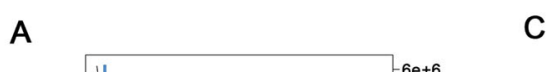

C
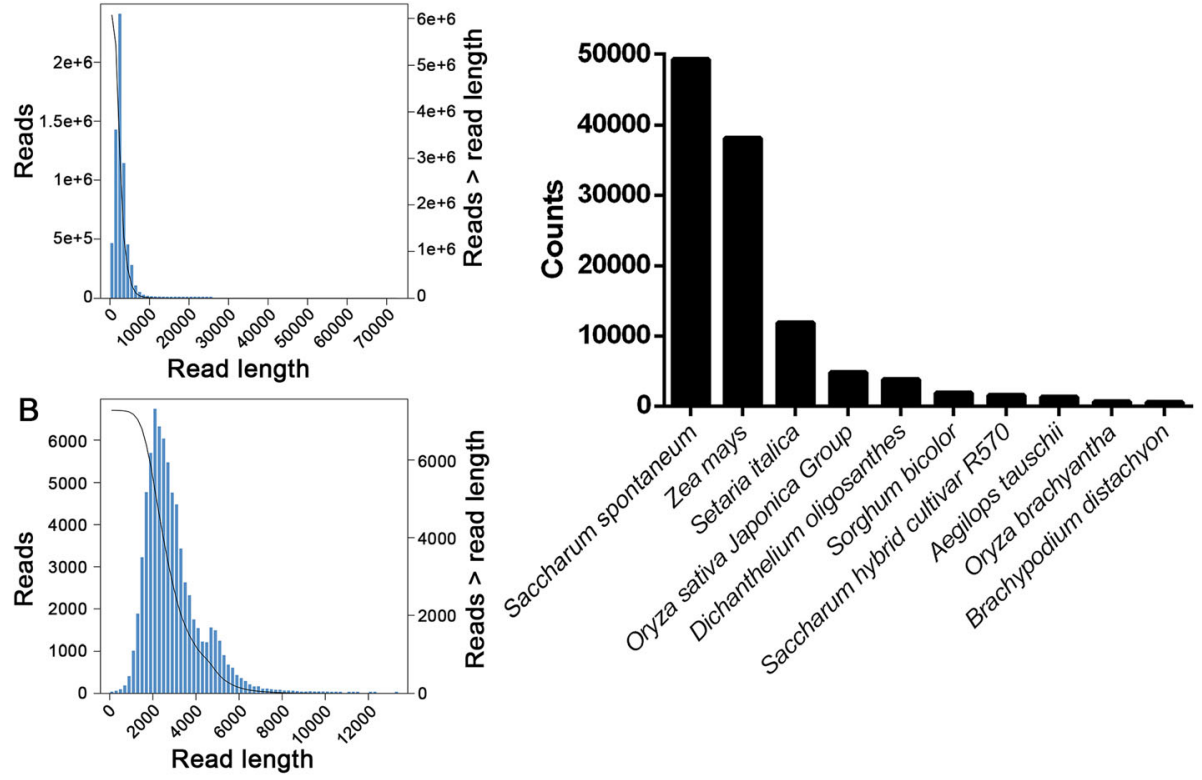

D

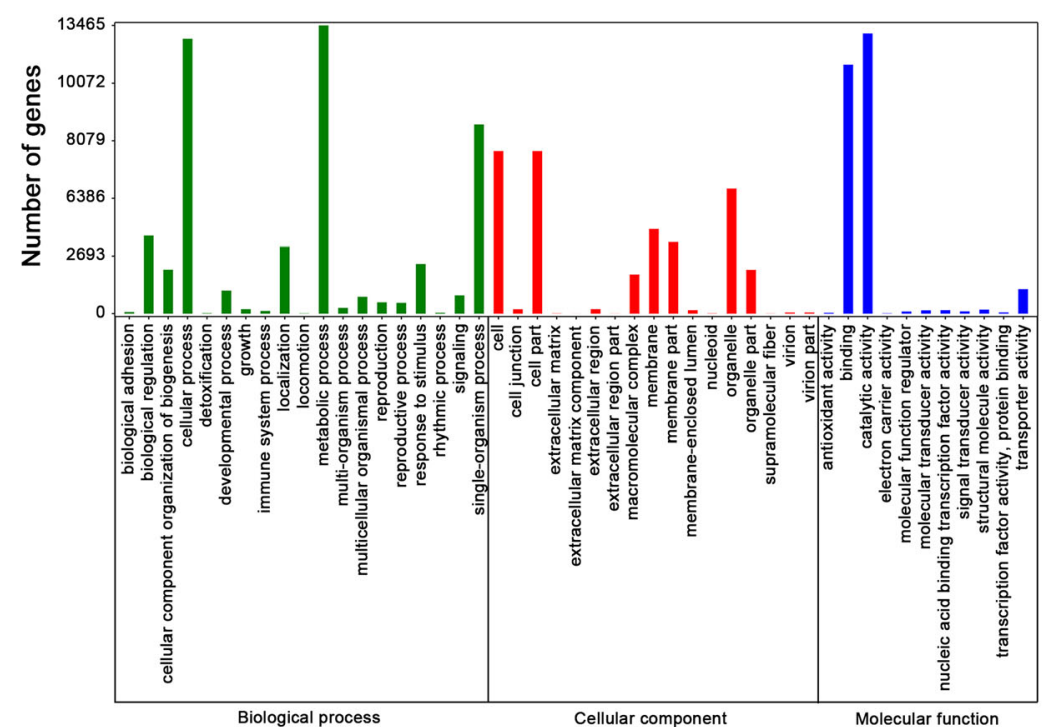

Fig. 2 Full-length transcriptome of internode of sugarcane. a Length distribution of reads generated from PacBio Sequel System sequencing. b Length distribution of isoforms generated from PacBio Sequel System sequencing. c Distribution of annotated genes from nr database in different species. $\mathbf{d}$ GO annotation of the isoforms

enriched gene function categories contained several pathways related to internode growth, including multiple pathways that participated in the production of metabolic products. Additionally, the gene modules included 33 genes that were highly correlated with the stage of six days post spraying in the DPC group, showing a potential role in the response to DPC. Among these genes, Stf0 sulfotransferase, cyclin-like F-box, and HOX12 were hub genes that may regulate all the other genes in this module. Further studies should focus on determining the function of these key genes in detail, especially with regards to controlling internode growth affected by DPC.

\section{Methods}

Sugarcane preparation

All the sugarcane samples used were bred at the Sugarcane Research Institute (SRI), Guangxi Academy of Agricultural Sciences in Nanning, China. The sugarcane variety, GT42, was sourced from the SRI Experimental 
A

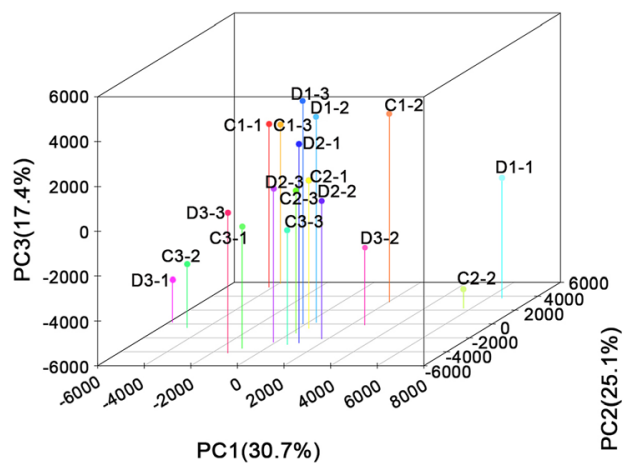

B

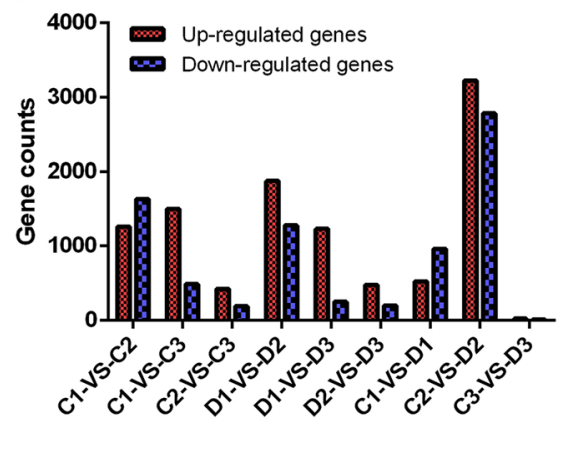

Fig. 3 Expression profile analysis based on RNA-seq result. a Principle component analyses of the 18 transcriptomes from the internodes of sugarcane on different days, in the control and DPC treatment groups, based on the FPKM. $\mathbf{b}$ Number of upregulated and downregulated genes of pairwise comparisons

Farm in Nanning, China. The team selected 10-monthold cane stalks to obtain buds in the middle internodes, which were then cut into setts from a single bud. The setts were incubated at $52{ }^{\circ} \mathrm{C}$ for $30 \mathrm{~min}$ to eliminate pathogenic bacteria and subsequently were planted in a moist sandbox and maintained in an artificial climate box (Essenscien, USA). The culturing conditions were as follows: temperature $28.0 \pm 0.1{ }^{\circ} \mathrm{C}$, humidity: $75 \pm 1.5 \% \mathrm{RH}$, photoperiod $12 \mathrm{~h}$ light and $12 \mathrm{~h}$ dark with $100 \%$ full light (light intensity 25,000 lx). Once the seedlings grew their first two leaves, they were transferred to plastic pots ( $35 \mathrm{~cm}$ width $\times 35 \mathrm{~cm}$ length $\times 50 \mathrm{~cm}$ height); in each pot, two seedlings were planted. After five days, the seedlings were randomly divided into two replicates. The seedlings were cultivated to the pre-elongation stage, which contained 9-10 leaves, defined as the early elongation stage. In this stage, the DPC group was sprayed with $200 \mathrm{mg} / \mathrm{L}$ DPC (Solarbio Life Science, Beijing,
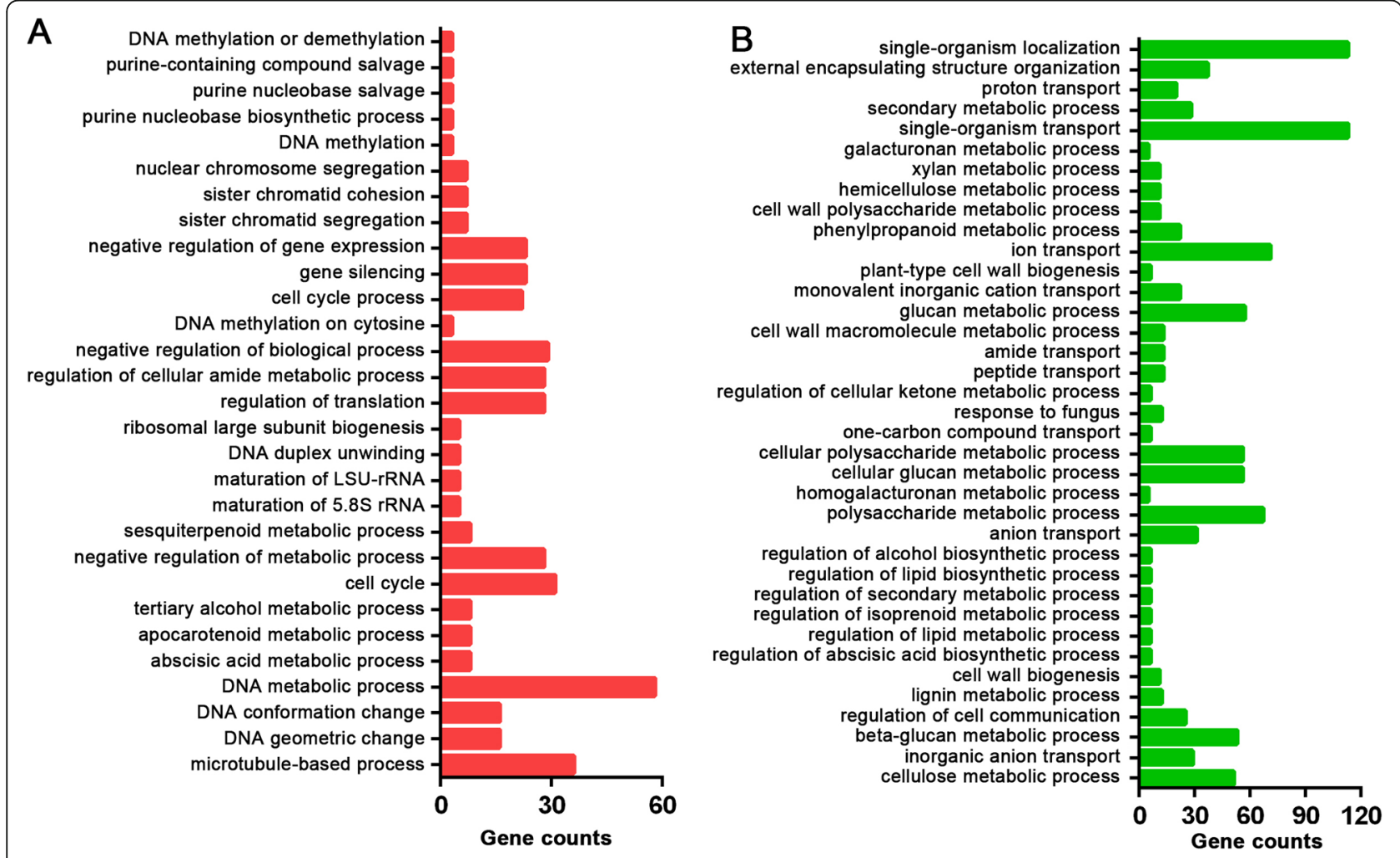

Fig. $4 \mathrm{GO}$ enrichment analysis result of upregulated genes $\mathbf{a}$ and downregulated genes $\mathbf{b}$ from C2-vs-D2 comparison 


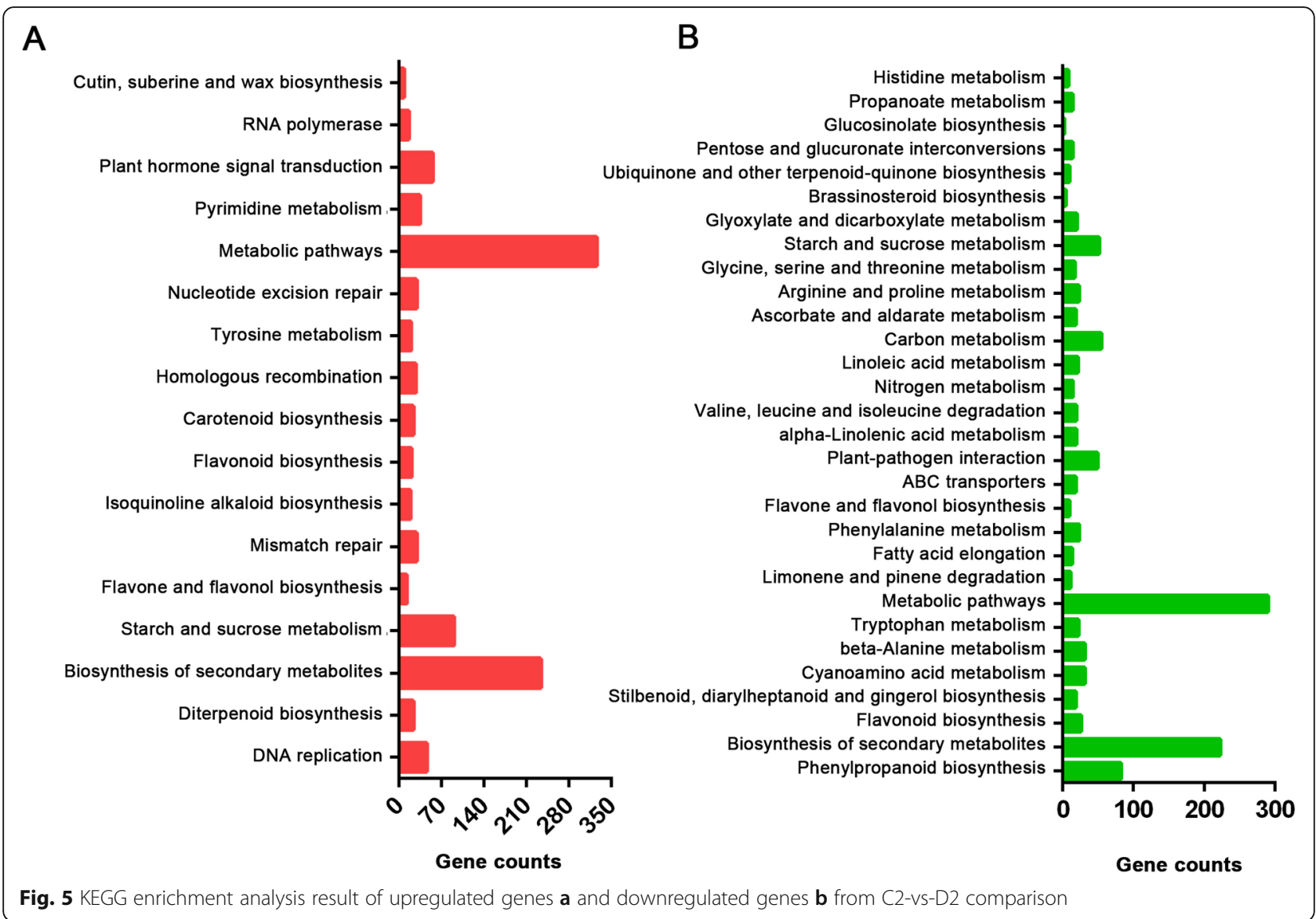

China) until the solution began to drip from the leaves. Water was sprayed on the control group in a similar pattern. All the sugarcane pots were placed in a greenhouse in 18 rows with $1.2 \mathrm{~m}$ width. The first three columns belonged to the control group and the last three columns belonged to the DPC group. At 3, 6, and 12 days post spraying, the third internodes were collected for further assays. Control samples from 3, 6, and 12 days post spraying were named $\mathrm{C} 1, \mathrm{C} 2$, and $\mathrm{C} 3$, respectively. Similarly, the samples of the DPC group from 3, 6, and 12 days post spraying were named D1, D2, and D3, respectively. All samples were stored at $-80{ }^{\circ} \mathrm{C}$ until RNA isolation. For each group, at different time points, three biological replicates were collected for analyses.

\section{Determination of growth performance}

Sugarcane growth performance was measured in the control and DPC groups. At 3, 6, and 12 days post spraying, we measured the stalk height from the soil surface to the dewlap of the youngest fully expanded leaf, as well as the length of the internodes. For each group, five plants were randomly chosen for measurement. The whole height and the first seven internode lengths (from the shoot apex of 10 matured plants) were measured as well.

\section{PacBio Iso-Seq}

To obtain an accurate reference for the genes in sugarcane, full-length transcriptome sequencing was performed. RNA libraries of internodes from one mature sugarcane at 10 months of age were prepared. The mRNAs were first enriched with oligo (dT) magnetic beads, and the full-length cDNAs were synthesized using Clontech SMARTer PCR cDNA Synthesis Kit (Pacific Biosciences, USA). From this, three libraries with different lengths (1-2 kb, 2-3 kb, and 3-6 kb) were constructed. Sequencing was performed on a PacBio Sequel System (Pacific Biosciences, USA) and the raw sequences were analyzed using SMRT Link v5.0.1 software. Based on the primer at $5^{\prime}$ and $3^{\prime}$ as well as ploy-A; the fulllength, non-full-length, chimeric, and non-chimeric categories were identified. The non-full-length sequences were polished using the Quiver algorithm, while the Illumina RNA-seq data were used to correct the low-quality sequences. The sequences were annotated using the $\mathrm{nr}$, SwissProt, COG/KOG, GO, and KEGG pathways, and 

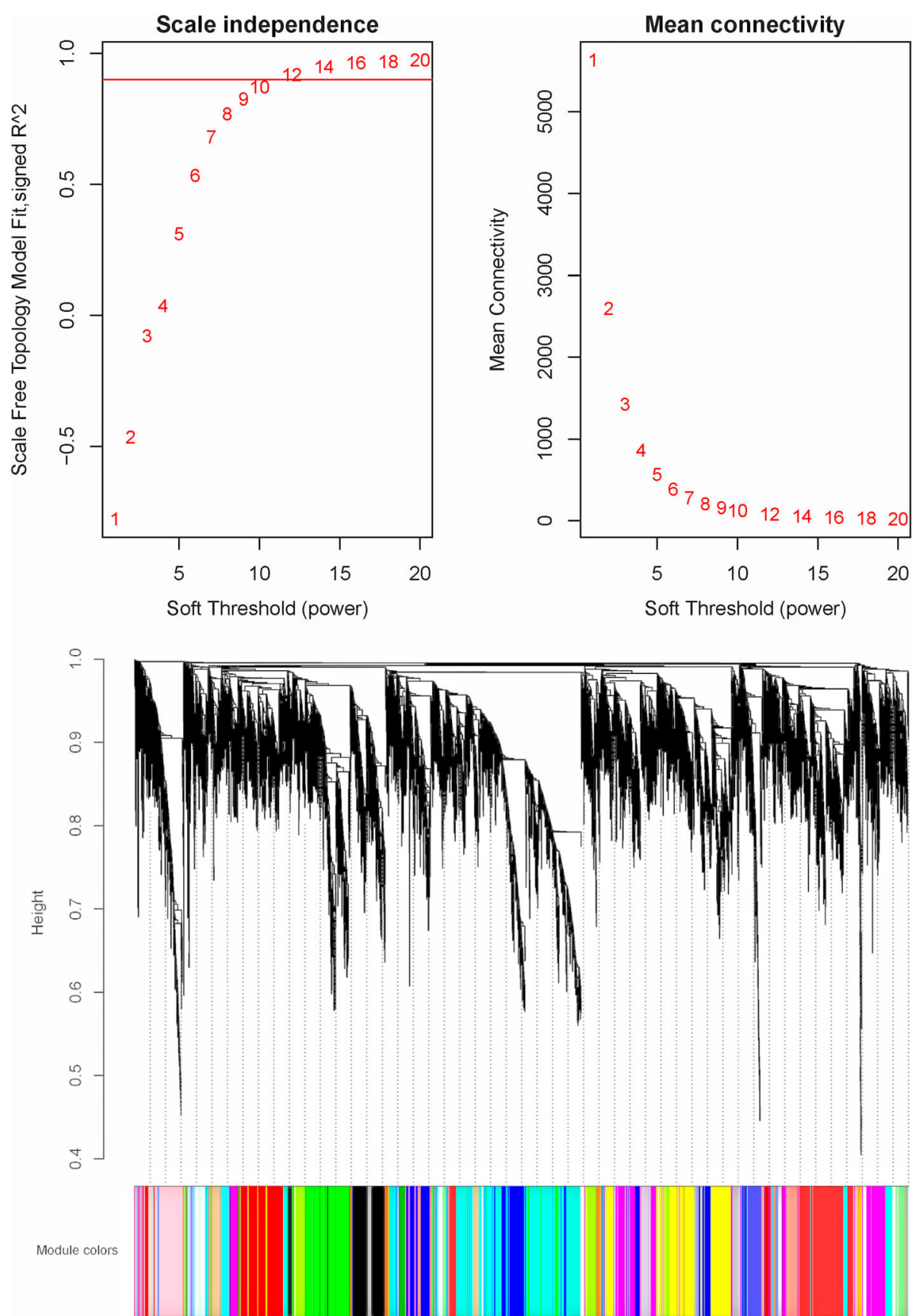

Fig. 6 WGCNA analysis of internode transcriptomes. a The influence of soft-thresholding power on scale-free fit index. $\mathbf{b}$ The influence of softthresholding power on the mean connectivity. c Cluster dendrogram of the dissimilarity clustering using a consensus topological overlap. Modules were assigned different colors

the unannotated sequences were further used for CDS prediction.

\section{Preparation of RNA-seq libraries}

Total RNA from three plants in each group was isolated using RNA Trizol (Invitrogen, Carlsbad, CA, USA) following the manufacturer's instructions. A total of six RNA-seq libraries (three from the control group and three from the DPC group) were prepared for nextgeneration sequencing. The quantity and integrity of the total RNA was assayed using an Agilent 2100 bioanalyzer (Agilent, Santa Clara, CA, USA). The mRNAs were enriched by oligo (dT) magnetic beads and fragmented using fragmentation buffer. First-strand cDNA was synthesized using random primers 6-bases long. The second-strand cDNA was then synthesized using DNA 


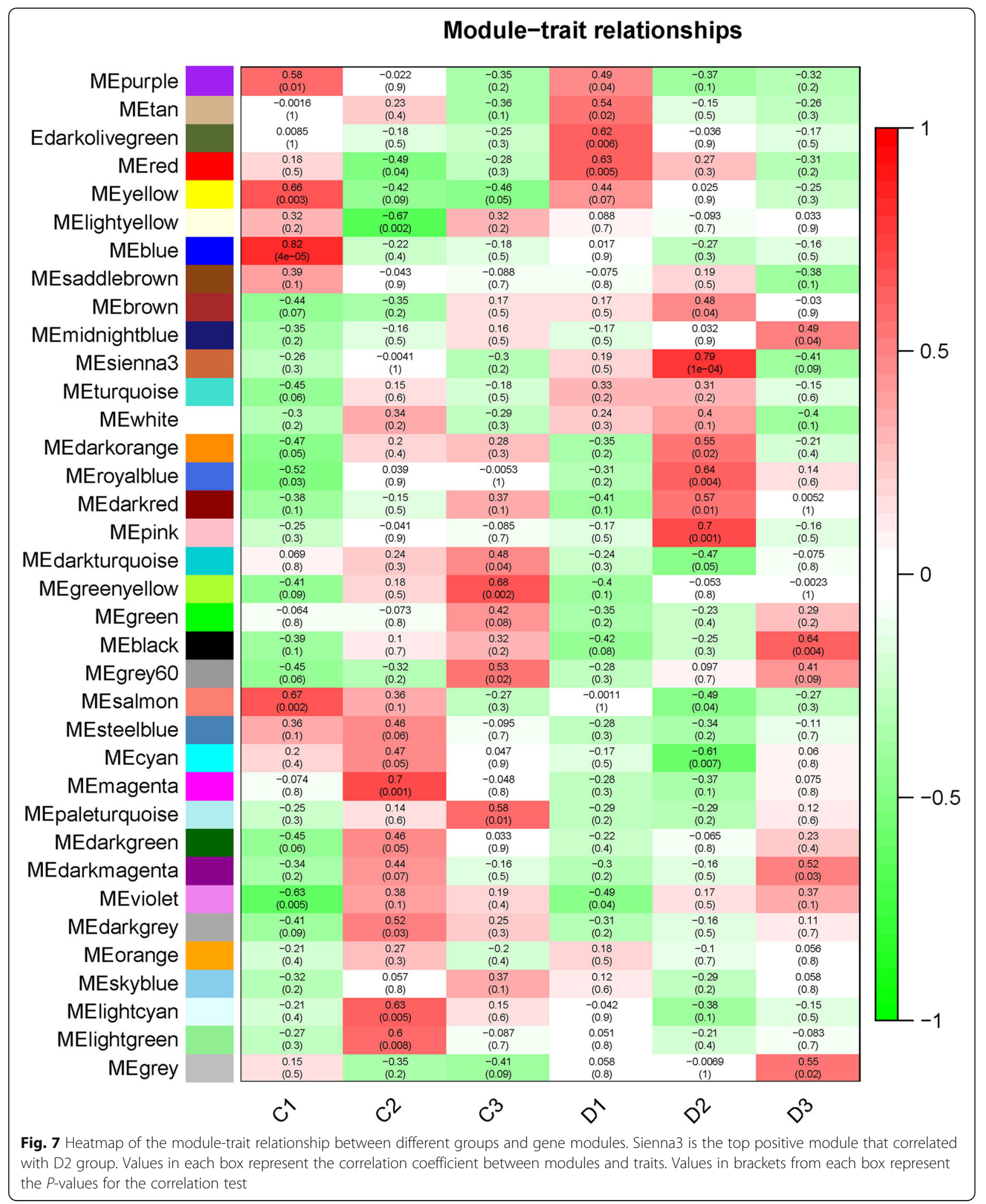

polymerase I. Subsequently, the cDNAs were isolated using a QIAquick PCR extraction kit (Qiagen, Hilden, Germany), and ligated with Illumina sequencing adapters. Finally, the cDNAs were purified using agarose gel electrophoresis and amplified by PCR to generate RNA-seq libraries. The RNA-seq was performed on an 


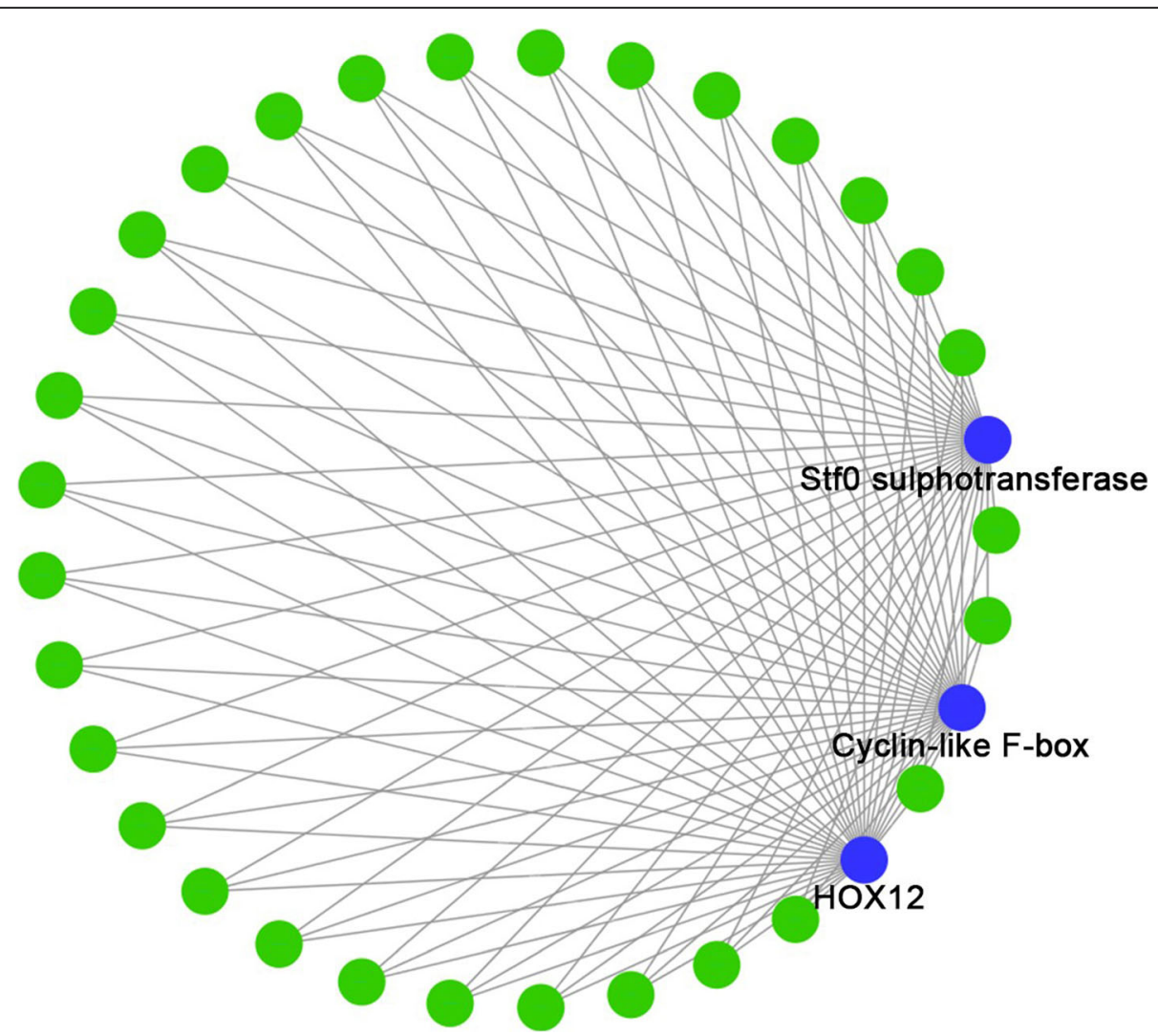

Fig. 8 Identification of hub gene in sienna3 by Cytoscape. Blue cycles represent the hub genes while green cycles show other genes. Grey lines show the correlations between the genes

Illumina HiSeq ${ }^{\text {ma }} 4000$ by Gene Denovo Biotechnology Co. (Guangzhou, China).

\section{Transcriptome mapping and differentially expressed gene (DEG) identification}

The sequencing adaptor was first trimmed, then lowquality reads with unknown nucleotides $(\mathrm{N})$ ratio $>10 \%$ or Q-value $\leq 20$ were removed. The retained reads were high-quality clean reads that were used for the following analyses. The clean reads were mapped to the reference transcriptome sequence using the full-length transcriptome by TOPHAT (version 2.0.9) [56], and the relative gene expression was calculated and normalized by Fragments Per Kilobase of transcript per Million mapped reads (FPKM). Furthermore, principal component analysis (PCA) was performed using the R package (http:// www.r-project.org/) to evaluate the reproducibility of the biological replicates. When the genes with a false discovery rate $(\mathrm{FDR})<0.05$ and $\log _{2}$ (fold change) $>1$ or $<-1$ were compared between the control group and DPC group, the genes were identified as DEGs.

\section{Functional annotation of DEGs}

To define the function of DEGs, enrichment analysis of Gene Ontology (GO) and Kyoto Encyclopedia of Genes and Genomes (KEGG) pathways were performed. The DAVID online tools (http://david.ncifcrf.gov/) were employed for the enrichment analysis. The GO items with adjusted $P \leq 0.001$ and KEGG pathways with $P \leq 0.001$ were considered to be significantly enriched.

\section{WGCNA}

The WGCNA was performed to identify key gene groups and hub genes based on the FPKM using the $\mathrm{R}$ package [57]. The data were first filtered according to the $25 \%$ variation based on variance (Standard Deviation/Mean) across samples. Further, the FPKM matrix of the retained genes was used to create a weighted adjacency matrix. The soft threshold power $(\beta)$ set at 10 , was selected to perform scale-free topology. The parameters for construction of the gene module were power $=8$, minimum module size $=30$, and branch merge cut height $=0.25$. The correlations between gene modules and treatment groups were evaluated using correlation 


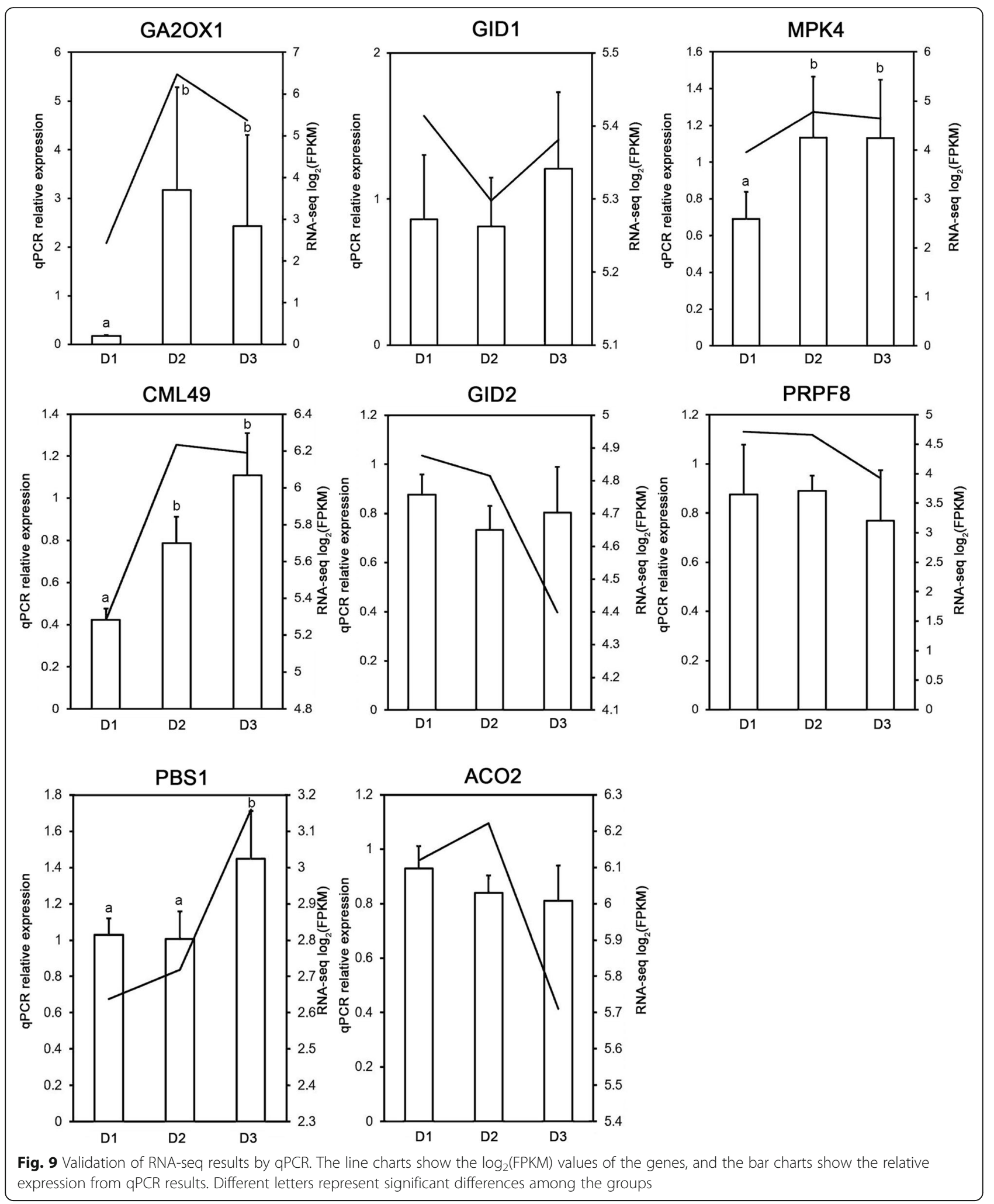

coefficients. The D2 group was the most notable treatment group owing to the large number of DEGs identified and we chose the top-correlated module (sienna3) of the D2 group for further analysis. First, GO and KEGG pathway enrichment analyses of the module were performed using KOBAS v3.0 (http://kobas.cbi.pku.edu. 

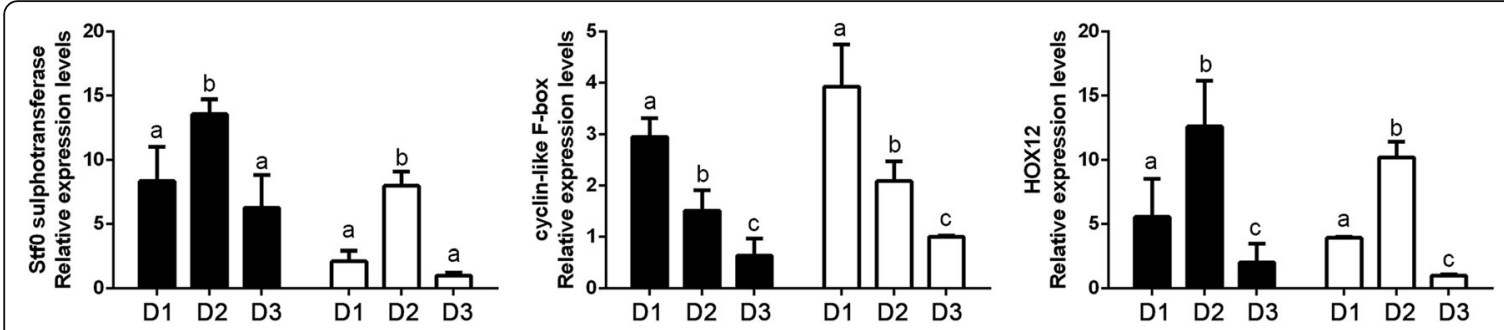

Fig. 10 Expression of the three hub genes including Stfo sulfotransferase $\mathbf{a}$, cyclin-like F-box $\mathbf{b}$, and HOX12 c in D1, D2, and D3 groups. The result of RNA-seq and qPCR was shown by black bars and white bars, respectively. Different letters represent significant differences among the groups

$\mathrm{cn} /$ ). The top three hub genes were identified using Cytohubba (http://apps.cytoscape.org/apps/cytohubba) and the network was plotted using Cytoscape v3.7.1.

\section{Real-time quantitative PCR analysis of genes (qPCR)}

Total RNA from internode tissues in the control and DPC groups were isolated and tested as described in section 2.1. The first-strain cDNAs were synthesized using the PrimeScript RT Reagent Kit with gDNA Eraser (Takara, Japan). Primers used for qPCR were designed by Primer Premier 5.0 (Applied Biosystems, Waltham, MA, USA) according to the gene sequences from the PacBio Iso-Seq (Additional file 1). The qPCR was performed on an Analytik Jena qTOWER 2.2 fluorescence quantitative PCR instrument (Germany). Furthermore, the PCR program used was as follows: $95{ }^{\circ} \mathrm{C}$ for $5 \mathrm{~min}$ for initial denaturation, followed by 45 amplification cycles at $95{ }^{\circ} \mathrm{C}$ for $10 \mathrm{~s}$ and $60{ }^{\circ} \mathrm{C}$ for $20 \mathrm{~s}$. Five biological replicates were tested for the amplification of each sample and EF1A was used as the control gene. To confirm the specificity of the PCR reaction, a melt curve analysis was performed. Additionally, the relative expression of the genes was calculated by the $2^{-\Delta \Delta C T}$ method.

\section{Data statistical analysis}

The growth rate, sugarcane height, internode length, and relative expression are presented as mean \pm standard deviation (SD). The significant differences among the groups were determined using one-way analysis of variance (ANOVA) and post hoc Tukey's test using SPSS statistical software package (v19.0, SPSS, Chicago, IL, USA). $P$ values $<0.05$ were considered to be significantly different.

\section{Supplementary Information}

The online version contains supplementary material available at https://doi. org/10.1186/s12864-020-07352-w.

Additional file 1. The primers used in this study.

Additional file 2. Summary of full-length transcriptome of sugarcane.

Additional file 3. Annotation results of isoforms from full-length transcriptome of sugarcane.
Additional file 4. GO enrichment analysis of DEGs.

Additional file 5. KEGG enrichment analysis of DEGs.

Additional file 6. Correlations between modules and the groups. (CSV 4 $\mathrm{kb})$

Additional file 7. Gene networks of the three hub genes including Stfo sulfotransferase, cyclin-like F-box, and HOX12. (CSV 2 kb)

\section{Abbreviations}

DPC: Mepiquat chloride; WGCNA: Weighted gene co-expression network analysis; GA: Gibberellin; CTK: Cytokinins; ABA: Abscisic acid; ETH: Ethyne; BR: Brassinosteroid; GA20-OX1: GA20-oxidase; GID1: Gibberellin receptor; SRI: Sugarcane Research Institute; GO: Gene Ontology; KEGG: Kyoto Encyclopedia of Genes and Genomes; FPKM: Fragments Per Kilobase of transcript per Million mapped reads; CCS: Circular-consensus sequence; FLNC: Full-length non-chimeric; PCA: Principal component analysis; SD: Standard deviations; ANOVA: One-way analysis of variance;

DEGs: Differentially expressed genes

\section{Acknowledgments}

Not applicable.

\section{Authors' contributions}

Authors RC, LQ, and JW conceived and designed the experiments; while YF, $H Z$, and SM collected the samples and cultured the sugarcane. Additionally, $\mathrm{ZZ}, \mathrm{HY}$, and TL analyzed the data after $\mathrm{XH}, \mathrm{MW}, \mathrm{PL}$, and $\mathrm{YL}$ performed the experiments. Furthermore, RC, YF, LQ, and JW wrote the manuscript, the final version of which all authors have reviewed and approved. The authors read and approved the final manuscript.

\section{Funding}

This work was supported by the National Natural Science Foundation of China (31701363, 31360312), Guangxi Natural Science Foundation (2018GXNSFAA138149 and 2017GXNSFBA198050), Special R \& D and joint research projects of the Chinese Academy of Sciences (KFJ-STS-QYZD-199-2), the Science and Technology Program of Guangxi (Guike AD19245080), and the National Key Research and Development Program of China (2019YFD1000503).

Availability of data and materials

Data for the sugarcane used in the RNA-Seq analysis are accessible at NCBI under the BioProject accession number PRJNA633918.

Ethics approval and consent to participate Not applicable.

Consent for publication

Not applicable.

Competing interests

The authors declare that they have no competing interests. 
Received: 28 July 2020 Accepted: 27 December 2020

Published online: 25 January 2021

\section{References}

1. Gray WM. Hormonal regulation of plant growth and development. PLoS Biol. 2004;2(9):e311 https://doi.org/10.1371/journal.pbio.0020311.

2. Vanstraelen M, Benková E. Hormonal interactions in the regulation of plant development. Annu Rev Cell Dev Biol. 2012;28:463-87 https://doi.org/10. 1146/annurev-cellbio-101011-155741.

3. Evans ML, Cleland RE. The action of auxin on plant cell elongation. Crit Rev Plant Sci. 1985;2(4):317-65 https://doi.org/10.1080/07352688509382200.

4. Huttly AK, Phillips AL. Gibberellin-regulated plant genes. Physiol Plant. 1995; 95(2):310-7 https://doi.org/10.1111/j.1399-3054.1995.tb00843.x.

5. Liu F, Xing S, Ma H, Du Z, Ma B. Cytokinin-producing, plant growthpromoting rhizobacteria that confer resistance to drought stress in Platycladus orientalis container seedlings. Appl Microbiol Biotechnol. 2013; 97(20):9155-64 https://doi.org/10.1007/s00253-013-5193-2.

6. Rai MK, Shekhawat N, Gupta AK, Phulwaria M, Ram K, Jaiswal U. The role of abscisic acid in plant tissue culture: a review of recent progress. Plant Cell Tissue Organ Cult. 2011;106(2):179-90 https://doi.org/10.1007/s11240-0119923-9.

7. $\quad Y u$ Z, Song $M$, Pei $H$, Jiang $L$, Hou Q, Nie C, Zhang $L$. The effects of combined agricultural phytohormones on the growth, carbon partitioning and cell morphology of two screened algae. Bioresour Technol. 2017;239: 87-96 https://doi.org/10.1016/j.biortech.2017.04.120.

8. Sun $Y$, Fan X-Y, Cao D-M, Tang W, He K, Zhu J-Y, He J-X, Bai M-Y, Zhu S, Oh $E$, et al. Integration of brassinosteroid signal transduction with the transcription network for plant growth regulation in Arabidopsis. Dev Cell. 2010;19(5):765-77 https://doi.org/10.1016/j.devcel.2010.10.010.

9. Giese G, Velasco-Cruz C, Roberts L, Heitman J, Wolf TK. Complete vineyard floor cover crops favorably limit grapevine vegetative growth. Sci Hortic. 2014;170:256-66 https://doi.org/10.1016/j.scienta.2014.03.011.

10. Yeshitela T, Robbertse P, Stassen P. Paclobutrazol suppressed vegetative growth and improved yield as well as fruit quality of Tommy Atkins' mango (Mangifera indica) in Ethiopia. N Z J Crop Hortic Sci. 2004;32(3):281-93 https://doi.org/10.1080/01140671.2004.9514307.

11. Wang N, Wang X, Shi J, Liu X, Xu Q, Zhou H, Song M, Yan G. Mepiquat chloride-priming induced salt tolerance during seed germination of cotton (Gossypium hirsutum L.) through regulating water transport and $\mathrm{K}^{+} / \mathrm{Na}^{+}$ homeostasis. Environ Exp Bot. 2019;159:168-78 https://doi.org/10.1016/j. envexpbot.2018.12.024

12. Gwathmey CO, Clement JD. Alteration of cotton source-sink relations with plant population density and mepiquat chloride. Field Crop Res. 2010; 116(1):101-7 https://doi.org/10.1016/j.fcr.2009.11.019.

13. Wang L, Mu C, Du M, Chen Y, Tian X, Zhang M, Li Z. The effect of mepiquat chloride on elongation of cotton (Gossypium hirsutum L.) internode is associated with low concentration of gibberellic acid. Plant Sci. 2014;225: 15-23 https://doi.org/10.1016/j.plantsci.2014.05.005.

14. Yeates S, Constable G, McCumstie T. Developing management options for mepiquat chloride in tropical winter season cotton. Field Crop Res. 2002; 74(2-3):217-30 https://doi.org/10.1016/S0378-4290(02)00005-9.

15. Davis TD, Curry EA, Steffens GL. Chemical regulation of vegetative growth. Crit Rev Plant Sci. 1991;10(2):151-88 https://doi.org/10.1080/ 07352689109382310

16. Rademacher W. Chemical regulators of gibberellin status and their application in plant production. Ann Plant Rev Online. 2018:359-403 https:// doi.org/10.1002/9781119312994.apr0541.

17. Reddy AR, Reddy KR, Hodges H. Mepiquat chloride (PIX)-induced changes in photosynthesis and growth of cotton. Plant Growth Regul. 1996;20(3):17983 https://doi.org/10.1007/BF00043305.

18. Tung SA, Huang Y, Ali S, Hafeez A, Shah AN, Song X, Ma X, Luo D, Yang G. Mepiquat chloride application does not favor leaf photosynthesis and carbohydrate metabolism as well as lint yield in late-planted cotton at high plant density. Field Crop Res. 2018;221:108-18 https://doi.org/10.1016/j.fcr. 2018.02.027

19. $\mathrm{Xu}$ X, Taylor HM. Increase in drought resistance of cotton seedlings treated with mepiquat chloride. Agron J. 1992;84(4):569-74 https://doi.org/10.2134/ agronj1992.00021962008400040005x.

20. Matsoukis A, Gasparatos D, Chronopoulou-Sereli A. Mepiquat chloride and shading effects on specific leaf area and K, P, Ca, Fe and Mn content of
Lantana camara L. Emirates J Food Agricult. 2015:121-5 https://doi.org/10 9755/ejfa.v27i1.17450.

21. Zhang S, Cothren J, Lorenz E. Mepiquat chloride seed treatment and germination temperature effects on cotton growth, nutrient partitioning, and water use efficiency. J Plant Growth Regul. 1990;9(1-4):195 https://doi. org/10.1007/BF02041962.

22. Roussos PA, Archimandriti A, Beldekou I. Improving in vitro multiplication of juvenile European chestnut (Castanea sativa mill) explants by the use of growth retardants. Sci Hortic. 2016;198:254-6 https://doi.org/10.1016/j. scienta.2015.11.039.

23. Goldemberg J, Coelho ST, Guardabassi P. The sustainability of ethanol production from sugarcane. Energy Policy. 2008;36(6):2086-97 https://doi. org/10.1016/j.enpol.2008.02.028.

24. Ukoskit K, Posudsavang G, Pongsiripat N, Chatwachirawong P, Klomsa-ard P, Poomipant $\mathrm{P}$, Tragoonrung S. Detection and validation of EST-SSR markers associated with sugar-related traits in sugarcane using linkage and association mapping. Genomics. 2019;111(1):9 https://doi.org/10.1016/j. ygeno.2018.03.019.

25. Fickett N, Gutierrez A, Verma M, Pontif M, Hale A, Kimbeng C, Baisakh N. Genome-wide association mapping identifies markers associated with cane yield components and sucrose traits in the Louisiana sugarcane core collection. Genomics. 2019;111(6):1794-801 https://doi.org/10.1016/j.ygeno. 2018.12.002.

26. Sindhu R, Gnansounou E, Binod P, Pandey A. Bioconversion of sugarcane crop residue for value added products-an overview. Renew Energy. 2016; 98:203-15 https://doi.org/10.1016/j.renene.2016.02.057.

27. Han $Y$, Watson M. Production of microbial Levan from sucrose, sugarcane juice and beet molasses. J Ind Microbiol. 1992;9(3-4):257-60 https://doi.org/ 10.1007/BF01569633.

28. Waclawovsky AJ, Sato PM, Lembke CG, Moore PH, Souza GM. Sugarcane for bioenergy production: an assessment of yield and regulation of sucrose content. Plant Biotechnol J. 2010;8(3):263-76 https://doi.org/10.1111/j.14677652.2009.00491.x

29. Chong BF, Mills E, Bonnett GD, Gnanasambandam A. Early exposure to ethylene modifies shoot development and increases sucrose accumulation rate in sugarcane. J Plant Growth Regul. 2010;29(2):149-63 https://doi.org/ 10.1007/s00344-009-9118-3.

30. Kuhnle J, Moore P, Haddon W, Fitch M. Identification of gibberellins from sugarcane plants. J Plant Growth Regul. 1983;2(1-4):59 https://doi.org/10. 1007/BF02042234

31. Rae AL, Grof CP, Casu RE, Bonnett GD. Sucrose accumulation in the sugarcane stem: pathways and control points for transport and compartmentation. Field Crop Res. 2005:92(2-3):159-68 https://doi.org/10. 1016/j.fcr.2005.01.027.

32. Glassop D, Roessner U, Bacic A, Bonnett GD. Changes in the sugarcane metabolome with stem development. Are they related to sucrose accumulation? Plant Cell Physiol. 2007;48(4):573-84 https://doi.org/10.1093/ $\mathrm{pcp} / \mathrm{pcm} 027$.

33. Jung J. Plant bioregulators: overview, use, and development. In: ACS Publications. 1985. https://doi.org/10.1021/bk-1985-0276.ch007.

34. Zummo G, Benedict J, Segers J. Effect of the plant growth regulator mepiquat chloride on host plant resistance in cotton to bollworm (Lepidoptera: Noctuidae). J Econ Entomol. 1984;77(4):922-4 https://doi.org/ 10.1093/jee/77.4.922.

35. Nuti RC, Viator RP, Casteel SN, Edmisten KL, Wells R. Effect of planting date, mepiquat chloride, and glyphosate application to glyphosate-resistant cotton. Agron J. 2006;98(6):1627-33 https://doi.org/10.2134/agronj2005.0360.

36. Bottino MC, Rosario S, Grativol C, Thiebaut F, Rojas CA, Farrineli L, Hemerly AS, Ferreira PCG. High-throughput sequencing of small RNA transcriptome reveals salt stress regulated microRNAs in sugarcane. PLoS One. 2013;8(3): e59423 https://doi.org/10.1371/journal.pone.0059423.

37. Ferreira TH, Gentile A, Vilela RD, Costa GGL, Dias LI, Endres L, Menossi M microRNAs associated with drought response in the bioenergy crop sugarcane (Saccharum spp.). 2012. 7(10): e46703. Published online 2012 Oct 11. doi: https://doi.org/10.1371/journal.pone.0046703.

38. Zhou Y, Liu Y, Luo Y, Zhong H, Huang T, Liang W, Xiao J, Wu W, Li L, Chen $M$. Large-scale profiling of the proteome and dual transcriptome in Nile tilapia (Oreochromis niloticus) challenged with low- and high-virulence strains of Streptococcus agalactiae. Fish Shellfish Immunol. 2020;100:386-96 https://doi.org/10.1016/j.fsi.2020.03.008. 
39. Wang $M$, Wang $L, P u L$, Li K, Feng $T$, Zheng $P$, Li S, Sun M, Yao Y, Jin L. LncRNAs related key pathways and genes in ischemic stroke by weighted gene co-expression network analysis (WGCNA). Genomics. 2020;112(3): 2302-8 https://doi.org/10.1016/j.ygeno.2020.01.001.

40. Do DN, Dudemaine P-L, Fomenky BE, Ibeagha-Awemu EM. Integration of miRNA weighted gene co-expression network and miRNA-mRNA coexpression analyses reveals potential regulatory functions of miRNAs in calf rumen development. Genomics. 2019;111(4):849-59 https://doi.org/10.1016/ j.ygeno.2018.05.009.

41. Qiu L, Chen R, Fan Y, Huang X, Luo H, Xiong F, Liu J, Zhang R, Lei J, Zhou H, et al. Integrated mRNA and small RNA sequencing reveals microRNA regulatory network associated with internode elongation in sugarcane (Saccharum officinarum L.). BMC Genomics. 2019;20(1):817 https://doi.org/10. 1186/s12864-019-6201-4.

42. Gonzalez-Garay ML. Introduction to isoform sequencing using pacific biosciences technology (Iso-Seq). In: Transcriptomics and gene regulation: Springer; 2016. p. 141-160. https://doi.org/10.1007/978-94017-7450-5_6.

43. Wang L, Liao J, Tan F, Tang S, Huang J, Li X, Yang R, Li Y, Huang H, Jing Y. Breeding of new high-yield, high-sugar and lodging-resistant sugarcane variety Guitang 42 and its high-yield cultivation technique. J Southern Agricult. 2015;46(8):1361-6.

44. Zhang J, Zhang X, Tang H, Zhang Q, Hua X, Ma X, Zhu F, Jones T, Zhu X, Bowers J. Allele-defined genome of the autopolyploid sugarcane Saccharum spontaneum L. Nat Genet. 2018;50(11):1565-73 https://doi.org/ 10.1038/s41588-018-0237-2.

45. Yang X, Luo Z, Todd J, Sood S, Wang J. Genome-wide association study of multiple yield traits in a diversity panel of polyploid sugarcane (Saccharum spp.). Plant Genome. 2020:e20006 https://doi.org/10.1002/tpg2.20006.

46. Garsmeur O, Droc G, Antonise R, Grimwood J, Potier B, Aitken K, Jenkins J, Martin G, Charron C, Hervouet C. A mosaic monoploid reference sequence for the highly complex genome of sugarcane. Nat Commun. 2018;9(1):1-10 https://doi.org/10.1038/s41467-018-05051-5.

47. Zhang D, Ren L, Yue J, Shi Y, Zhuo L, Wang L, Shen X. RNA-Seq-based transcriptome analysis of stem development and dwarfing regulation in Agapanthus praecox ssp. orientalis (Leighton) Leighton. Gene. 2015;565(2): 252-67 https://doi.org/10.1016/j.gene.2015.04.013.

48. Douglas CJ. Phenylpropanoid metabolism and lignin biosynthesis: from weeds to trees. Trends Plant Sci. 1996;1(6):171-8 https://doi.org/10.1016/ 1360-1385(96)10019-4.

49. Herrmann K. Flavonols and flavones in food plants: a review. Int J Food Sci Technol. 1976;11(5):433-48 https://doi.org/10.1111/j.1365-2621.1976. tb00743.x.

50. Ringli C, Bigler L, Kuhn BM, Leiber R-M, Diet A, Santelia D, Frey B, Pollmann $\mathrm{S}$, Klein M. The modified flavonol glycosylation profile in the Arabidopsis rol1 mutants results in alterations in plant growth and cell shape formation. Plant Cell. 2008;20(6):1470-81 https://doi.org/10.1105/tpc.107.053249.

51. Xu Y, Wang G, Cao F, Zhu C, Wang G, El-Kassaby YA. Light intensity affects the growth and flavonol biosynthesis of Ginkgo (Ginkgo biloba L.). New For. 2014;45(6):765-76 https://doi.org/10.1007/s11056-014-9435-7.

52. Pék Z, Daood H, Nagyné MG, Berki M, Tóthné MM, Neményi A, Helyes L. Yield and phytochemical compounds of broccoli as affected by temperature, irrigation, and foliar sulfur supplementation. HortScience. 2012; 47(11):1646-52 https://doi.org/10.21273/HORTSCl.47.11.1646.

53. Hirschmann F, Krause F, Papenbrock J. The multi-protein family of sulfotransferases in plants: composition, occurrence, substrate specificity, and functions. Front Plant Sci. 2014:5(556) https://doi.org/10.3389/fpls. 2014.00556

54. Boycheva I, Vassileva V, Revalska M, Zehirov G, lantcheva A. Cyclin-like F-box protein plays a role in growth and development of the three model species Medicago truncatula, Lotus japonicus, and Arabidopsis thaliana. Res Reports Biol. 2015;6:117 https://doi.org/10.2147/RRB.S84753.

55. Gao S, Fang J, Xu F, Wang W, Chu C. Rice HOX12 regulates panicle exsertion by directly modulating the expression of ELONGATED UPPERMOST INTERNODE1. Plant Cell. 2016;28(3):680-95 https://doi.org/10. 1105/tpc.15.01021

56. Trapnell C, Pachter L, Salzberg SL. TopHat: discovering splice junctions with RNA-Seq. Bioinformatics. 2009:25(9):1105-11 https://doi.org/10.1093/ bioinformatics/btp120.
57. Langfelder $P$, Horvath S. WGCNA: an R package for weighted correlation network analysis. BMC Bioinform. 2008;9(1):559 https://doi.org/10.1186/14712105-9-559.

\section{Publisher's Note}

Springer Nature remains neutral with regard to jurisdictional claims in published maps and institutional affiliations.
Ready to submit your research? Choose BMC and benefit from:

- fast, convenient online submission

- thorough peer review by experienced researchers in your field

- rapid publication on acceptance

- support for research data, including large and complex data types

- gold Open Access which fosters wider collaboration and increased citations

- maximum visibility for your research: over $100 \mathrm{M}$ website views per year

At BMC, research is always in progress.

Learn more biomedcentral.com/submissions 